\title{
Complutum
}

ISSN: 1131-6993

\section{Contrebia Carbica. Estudio del sistema defensivo para un debate sobre poliorcética y urbanismo en la Celtiberia de los siglos II y I a.C.}

\author{
Francisco Romeo Marugán ${ }^{1}$
}

Recibido: 18 de mayo de 2017 / Aceptado: 25 de octubre de 2018.

Resumen. Analizamos el sistema defensivo de Contrebia Carbica mediante la fotografía aérea histórica. Los resultados de este análisis serán la base para reflexionar sobre la aparición en Celtiberia de ciudades con rasgos similares durante el siglo II a.C. Se trata de un fenómeno que relacionamos con la influencia itálica en esta zona, proponiendo la Paz de Graco como detonante de una transformación radical e irreversible de la cultura indígena que acabara transformando su urbanismo, y por tanto su forma de vida, en la segunda mitad del siglo II a.C.

Palabras clave: Contrebia Carbica; Celtiberia; Sistemas defensivos; Urbanismo; Frontera; Estrategia.

[en] Contrebia Carbica. Study of the defensive system for a reflection on poliorcetic and urbanism of 2 nd and 1 st centuries BC in Celtiberia

\begin{abstract}
This paper provides a study of the defensive system of Contrebia Carbica based on the aerial photography series. The result of this analysis allow us to think about the development of analogous cities during the 2nd century in Celtiberia. It is a fact that we link to he Italic influence in this area. In this way, the Gracchus' peace can be the trigger for a dramatic and irreversible change in the indigenous culture which will transform the urban planning, and thus the way of life, during the second part of the second century B.C.
\end{abstract}

Keywords: Contrebia Carbica; Celtiberia; Defensive Systems; Urban Planning; Frontier; Strategy.

Sumario: 1. Introducción. 2. El sistema defensivo de contrebia carbica. 3. Las alineaciones del recinto meridional. 4. Análisis táctico y estratégico del sistema defensivo. 5. ¿Non bis idem? 6. Contrebia Carbica y su contexto histórico. 7. Conclusiones.

Cómo citar: Romero Marugán, F. (2018): Contrebia Carbica. Estudio del sistema defensivo para un debate sobre poliorcética y urbanismo en la Celtiberia de los siglos II y I a.C. Complutum, 29(1): 171-190.

\section{Introducción.}

El yacimiento arqueológico de Fosos de Bayona se encuentra en la margen izquierda del río Cigüela, en el término municipal de Huete, Cuenca. Esta ciudad celtibérica se extiende a lo largo de más de un kilómetro sobre una amplia plataforma caliza (Fig. 1), y ha sido identificada como la Contrebia Carbica de las fuentes (Abascal y Ripollés 2000, Lorrio y Sánchez 2000-2001, Almagro y Lorrio 2006-2007, Burillo 2007: 207, Lorrio 2012a: 247-249; Lorrio et al. 2013: 298-299).
El yacimiento posee unas dimensiones considerables. Con un eje de $1250 \mathrm{~m}$ posee una superficie de 34,29 Ha distribuidas en tres recintos independientes. Cada recinto está separado del contiguo por muralla y foso. En un reciente trabajo (Romeo 2017) tuvimos oportunidad de comprobar que prácticamente toda la ciudad aparece rodeada por dos fosos paralelos, distantes entre 80 y 150 m entre sí, lo que lleva la superficie total de Contrebia Carbica a $64 \mathrm{Ha}$, creando un sistema defensivo particular (Fig. 2).

\footnotetext{
Dirección General de Cultura y Patrimonio del Gobierno de Aragón.

franciscoromeomarugan@gmail.com
} 


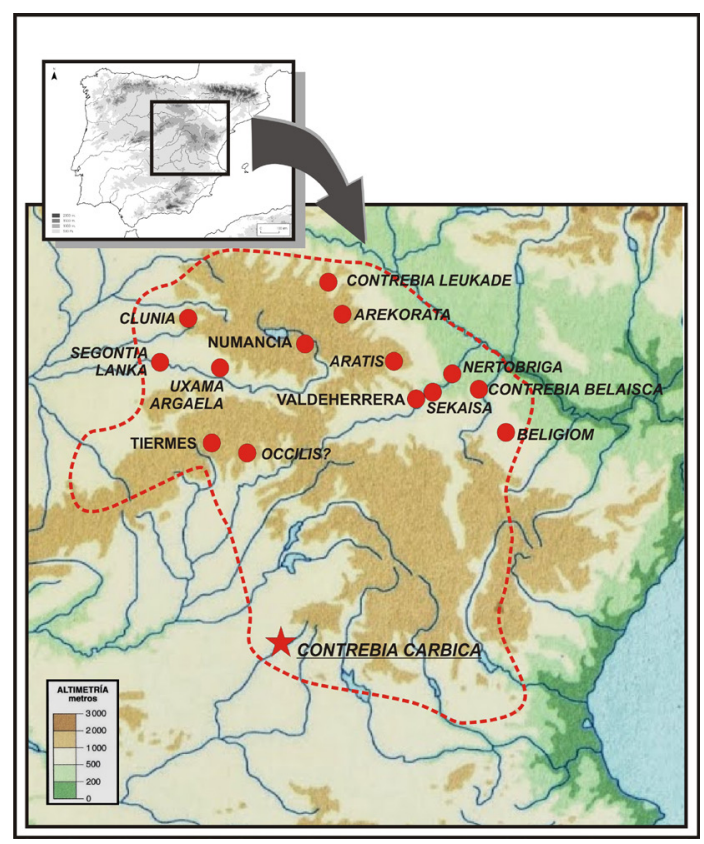

Figura 1. Situación de Contrebia Carbica.

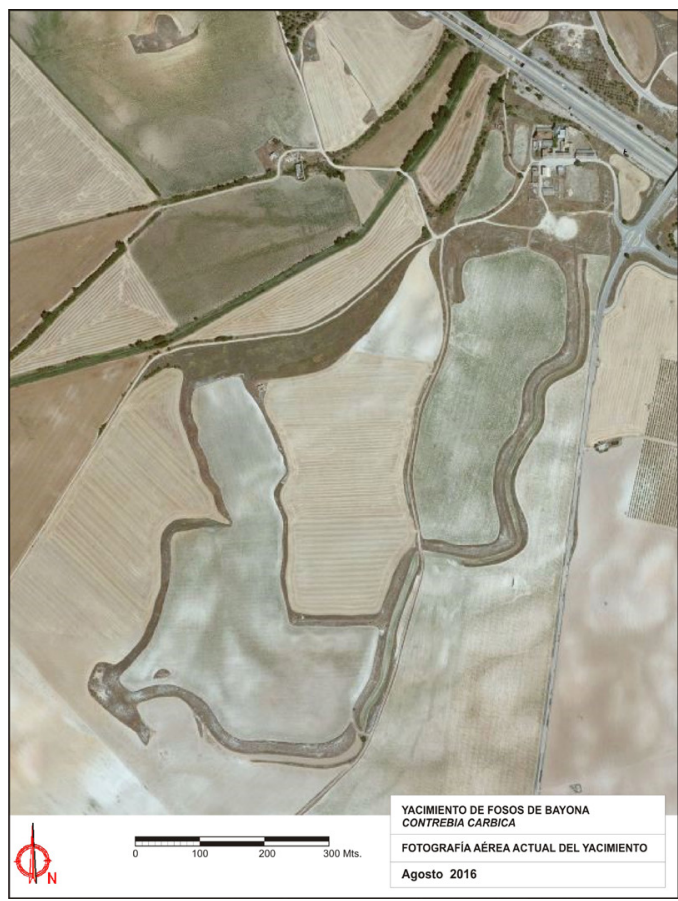

Figura 2. Imagen aérea actual de Contrebia Carbica.

Los materiales recuperados en las intervenciones arqueológicas realizadas y en superficie indican un origen para la ciudad de finales del siglo III a.C. así como una destrucción violenta en contexto sertoriano (Mena et al. 1988: 183, Lorrio 2012a: 255), aunque se ha propuesto mediados del I a.C. para la desaparición de la ciudad (Abascal y Ripollés 2000: 34, Lorrio 2012a: 262, nota 104).

\section{El sistema defensivo de Contrebia Carbica.}

Antecedentes: las intervenciones arqueológicas sobre el sistema defensivo.

Sobre Contrebia Carbica se han realizado tres campañas de excavación (Fig. 3), en 1976, 1982 y 1984. En 1976 se intervino en el segundo recinto, aunque esta campaña permane- 
ce inédita (Mena et al. 1988: 183 y 186). En 1982 se realizaron sondeos arqueológicos en la zona central del segundo recinto, en la puerta localizada en 1976, en un tramo de la muralla al oeste y en otra posible puerta, al sur del yacimiento (Gras et al. 1984, figura 3). Estos trabajos continuaron en 1984, ampliando la intervención sobre la puerta septentrional (Mena

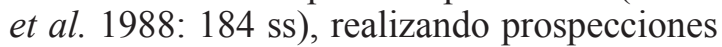
eléctricas, magnéticas y gravimétricas en distintos puntos de la ciudad (Hernández et al.
1992), e interviniendo en un tramo del foso cuyas paredes, según los directores de la intervención, estaban enlucidas con yeso (Gras et al. 1984: 55). A los pies de la muralla y en paralelo a la misma se dispone un antemuro (Mena et al. 1988: 184). Al sur del yacimiento se comprobó la existencia de un muro que conecta el lienzo interior con el exterior de la muralla, que se identificó como una torre en las inmediaciones de una puerta (Gras et al. 1984: 55) (Fig. 3, no 5).

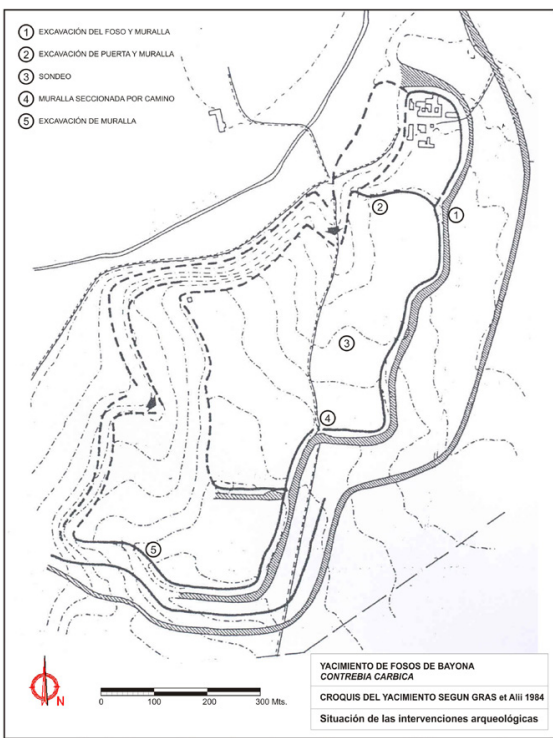

Figura 3. Croquis del yacimiento y situación de las intervenciones arqueológicas (Gras et alii 1984)

\section{Los fosos exteriores, interiores y transver- sales}

Si algo llama la atención de este yacimiento son sus enormes dimensiones, puestas de manifiesto por las murallas de los tres recintos y por el foso que da nombre al lugar: Fosos de Bayona. Sobre el terreno y a simple vista se reconoce este largo foso a los pies de un talud coronado por la muralla (Fig. 4). Su anchura varía entre 15 y 19 $\mathrm{m}$, algo habitual para fechas posteriores al siglo III a.C. (Romeo 2002: 162).

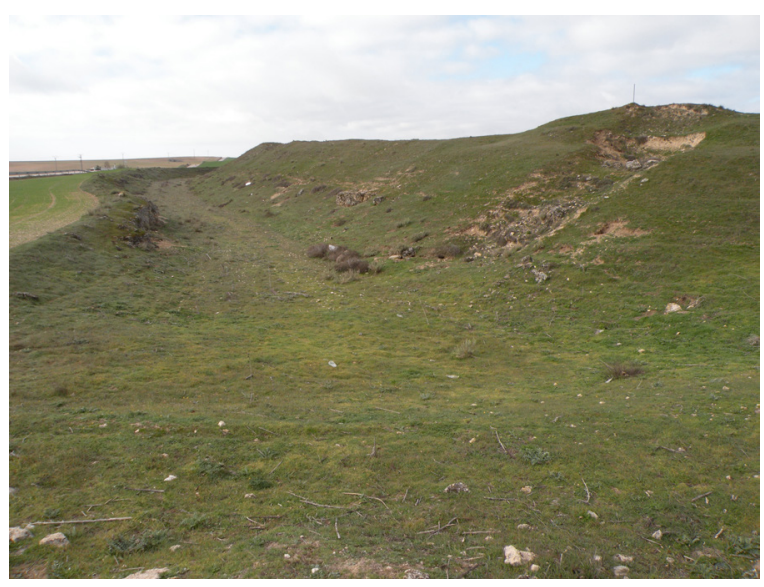

Figura 4. Aspecto actual del primer foso y la muralla de la ciudad. 
El foso posee un primer tramo vertical que corta una capa de roca caliza, para adoptar después una marcada sección en V (Gras et al. 1984: 55). En ocasiones estos fosos presentan un perfil asimétrico (Vicente et al. 1985, Romeo y Royo 2015: 346-347), siendo conocidos en las fuentes clásicas como fossa punica (Romeo 2005: 201). Los datos obtenidos indican la presencia de este perfil asimétrico en el foso de Contrebia Carbica, permitiéndonos reconstruir una sección del foso y la muralla en el punto donde se intervino en 1984 (fig. 5).

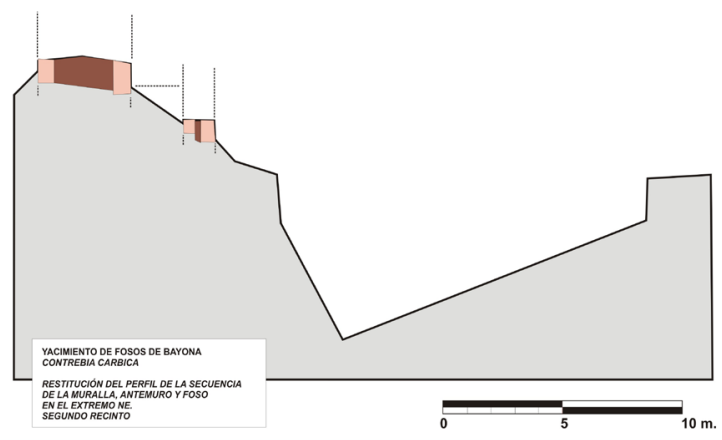

Figura 5. Restitución de la sección de la muralla y el foso de la ciudad según el autor.

El estudio de las imágenes aéreas ha permitido reconocer un complejo sistema formado por varios fosos. Tanto en la fotografía publicada en 1984 (Fig. 6) como en la de 1956 se reconoce una marcada línea o crop-mark positiva (Musson 2005; Mayoral 2016: 28-29) que interpreta- mos como una línea de foso exterior, alejada de la muralla. Los cálculos realizados proporcionan una anchura para el mismo de entre 9 y 15 $\mathrm{m}$, variaciones que pueden deberse tanto a los procesos de puesta en cultivo (Boismier 1997) como a diferentes anchuras en origen.

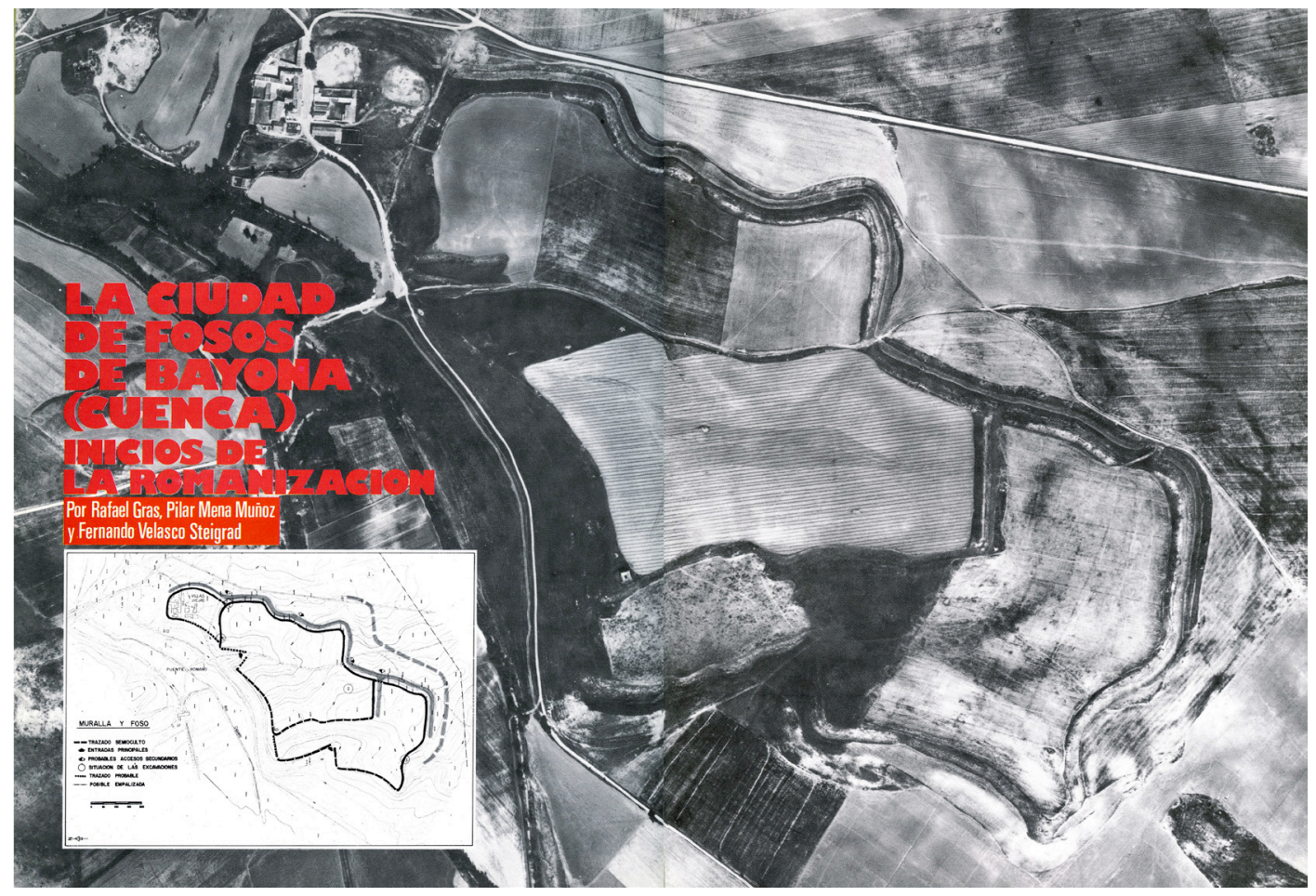

Figura 6. Fotografía aérea detallada de la ciudad (Gras et alii 1984) 
La distancia entre foso exterior y la muralla fluctúa entre 80 y $150 \mathrm{~m}$. Lejos de resultar algo excepcional, la revisión de varios asentamientos de los siglos III al I a.C. está permitiendo reconocer segundas y hasta terceras líneas de fosos a distancias similares. Esta distancia es insuficiente para defenderse de los arcos o de la artillería de torsión, sin embargo resulta excesiva para defenderse de armas arrojadizas como pila o similares. Recientemente hemos concluido que ésta es una distancia óptima para defenderse de ataques con proyectiles de honda, siendo ésta una de las armas más utilizadas para el ataque y asedio a los sistemas defensivos a partir de finales del III a.C. (Romeo 2017). Hay que recordar que en Contrebia Carbica se han recuperado numerosos proyectiles de honda de plomo (Gras et al. 1984: 53, Lorrio 2012a: 254).

A estos fosos hay que sumar los que separan los recintos entre sí. El foso que aísla el recinto norte posee $130 \mathrm{~m}$ de longitud y $10 \mathrm{de}$ anchura, mientras que el que defiende el recinto central del sur es visible en un tramo recto de $142 \mathrm{~m}$, con una anchura aproximada de 18 m. Este sistema crea una compartimentación que permitiría la resistencia de un recinto aunque haya caído el inmediato. Se trata de un recurso conocido y utilizado en la Grecia clásica (Lawrence 1979: 148-150; Gros 1992: 213 y Moret 1996: 245) y su función era la de dividir el espacio urbano para secuenciar y facilitar la defensa en el caso de la caída de un sector de la ciudad (Romeo 2005: 198). No obstante, la preexistencia de este recurso en la Península ibérica (Royo y Romeo 2015: 364) permite considerar este sistema como una evolución propia de la poliorcética peninsular (Romeo 2002: 175).

A este mismo principio, aunque a otro nivel táctico, pueden responder una serie de líneas visibles en imágenes aéreas que conectan perpendicularmente los dos fosos perimetrales (Fig. 7), unos crop-marks positivos con una anchura similar al foso exterior. Estos posibles fosos dividen en tramos el campo defensivo, compartimentando el ataque para facilitar la concentración de defensores.

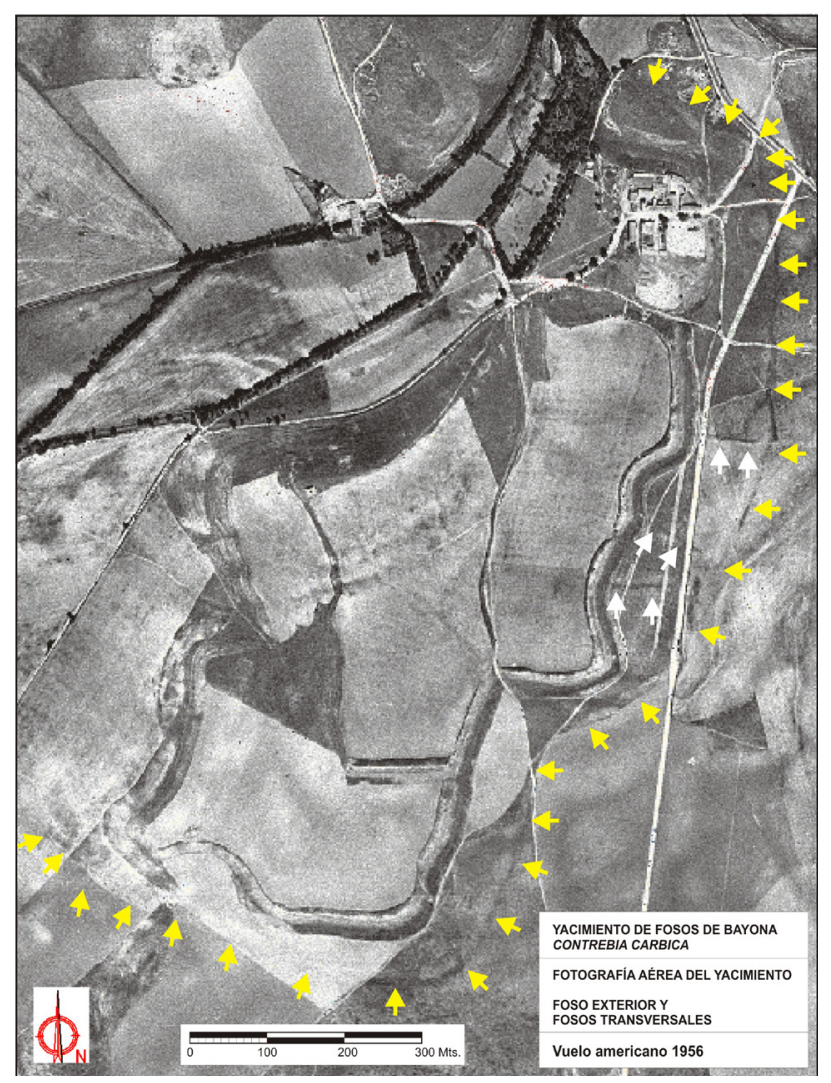

Figura 7. Fotografía aérea con indicación del foso exterior y los fosos transversales. 
El ataque a las ciudades por varios puntos al mismo tiempo era una táctica que buscaba dividir a los defensores para debilitar una zona sobre la que concentrar el ataque principal. Para ello era esencial la sorpresa y rapidez de desplazamiento de los asaltantes, por lo que las barreras y obstáculos en el perímetro de la ciudad ofrecen una ventaja táctica a los defensores, que intentarán concentrar su contingente en una zona concreta con mayor rapidez que el enemigo.

Esta interpretación sería mucho menos plausible si no hubiésemos identificado recursos similares en otra ciudad celtibérica, Aratis, donde aparece el foso dividido en tramos mediante la disposición de tres barreras perpendiculares formadas por fragmentos de roca de grandes dimensiones (Fatás et al. 2015: 25, fig. 3).

No hemos podido reconocer en ningún punto del foso indicio de los revestimientos de yeso citados en su momento (Mena et al. 1988: 184), algo que sería un caso único en la Península Ibérica. Esto nos lleva a suponer que estas paredes no estarían revestidas de yeso, pudiendo residir la explicación en un proceso natural, como veremos más adelante (vid. infra).

\section{EI antemuro}

Las excavaciones de 1984 localizaron un muro a los pies de la muralla, en paralelo a la misma y dispuesto sobre la escarpa del foso (Fig. 3, $\mathrm{n}^{\mathrm{o}} 1$ ) (Mena et al. 1988: 184), estructura que se puede reconocer a simple vista en varios tramos de la ladera. Estos elementos se consideraban anecdóticos en los sistemas defensivos peninsulares (Badie et al. 2000: 124) y de origen exclusivamente helenístico (Moret 1996: 214), y su presencia en yacimientos púnicos como La Fonteta (González 2011: 21), confirma igualmente su uso en la poliorcética fenopúnica. No obstante, el antemuro localizado en el yacimiento del Alto de la Cruz de Zaragoza con una cronología entre el 650 y el 550 a.C. y ausencia de cualquier tipo de importaciones (Picazo y Rodanés 2009: 264, fig.14), obliga a poner entre paréntesis estas influencias foráneas, púnicas o griegas, para estos antemuros defensivos. Su presencia cada vez más habitual en los yacimientos indígenas del valle del Ebro y del litoral mediterráneo (Lorrio 2012b: 79 fig. 12) así como lo intuitivo de la solución, hace que nos decantemos por un origen descentralizado para estos elementos que potencian la capacidad defensiva de los asentamientos, proporcionando mayor estabilidad estructural a la muralla, potenciando la escarpa del foso y dificultando las posibles labores de zapa del contingente enemigo.

\section{La muralla}

La muralla de Contrebia Carbica dibuja y define el paisaje de la zona, permitiendo identificar con nitidez los límites de la ciudad. En muchos tramos se sigue alzando como un verdadero $a g$ ger entre los campos de cultivo y el foso (Fig. 8). Allá donde se puede reconocer, aparece formada por dos lienzos que delimitan un espacio interno relleno de piedras y tierra, con una anchura de $340 \mathrm{~cm}$. El hecho de que la muralla se eleve todavía sobre la superficie del interior de la ciudad parece sugerir que en su momento se encontraba separada de la trama urbana, diferenciándose de este modo de las tradiciones urbanísticas anteriores (Royo y Romeo 2015: 378-382), disposición que se comienza a reconocer en otras ciudades celtíberas como Numancia (Jimeno et al. 2017: 56-57).

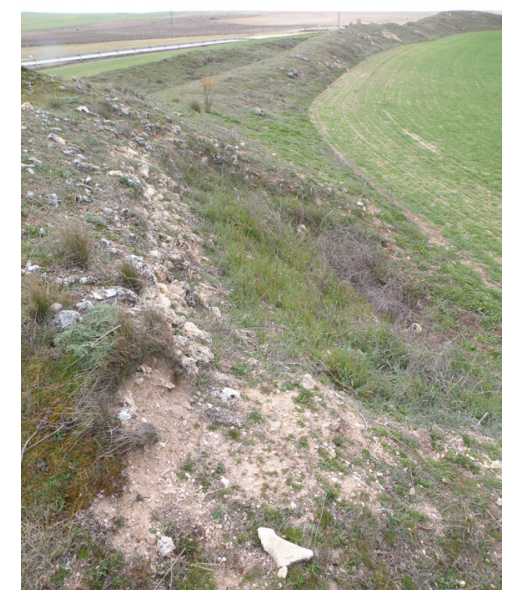

Figura 8. Aspecto actual del interior de la muralla.

La notable anchura de esta estructura y la existencia de muros que conectan ambos lienzos entre sí (Gras et al. 1984: 55; fig 3, punto 5 , imagen 4) parecen sugerir que podemos estar ante una muralla de cajones. Este sistema constructivo se viene considerando de origen púnico (Moret 1996: 213-214, Berrocal 2004: 40 o González 2011: 21). La revisión de varios sistemas defensivos hace que su presencia en la Península Ibérica sea cada vez más habitual en contextos del siglo III y II a.C. (Berrocal et al. 2014: 282, Cerdeño et al. 2014: 307).

Al igual que en el caso del foso, en su momento se precisó que los mampuestos y el relleno de la muralla aparecían trabados con mortero de cal (Mena et al. 1988: 184). Sobre el terreno pudimos desestimar su utilización, 
identificando en su lugar un proceso natural producido por la reacción de las pluviales con la química del sustrato y las piedras del relleno: ripios y mampuestos de calizas de tamaño medio y pequeño (Fig. 9), un fenómeno similar al que se pudo comprobar en el caso del Cabezo de Alcalá de Azaila (Beltrán 2013: 363).

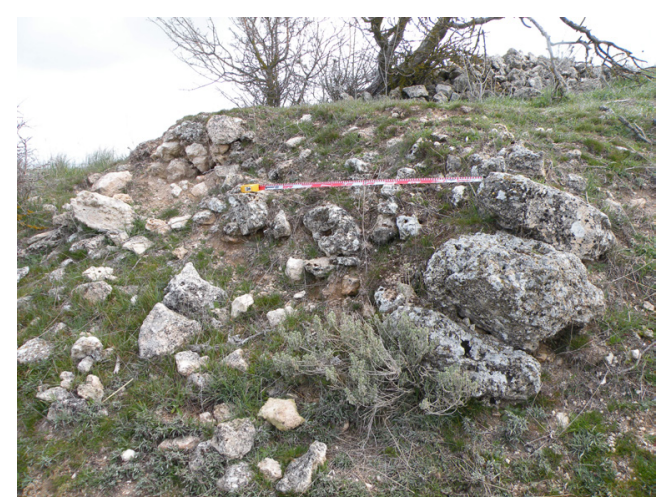

Figura 9. Aspecto actual de la muralla seccionada.

El aparejo con el que se resuelve el lienzo externo se había definido como formado por piezas careadas de piedra caliza local de talla regular (Gras et al. 1984: 52). La tónica dominante es solucionar la obra con sillares careados de tamaño medio, en ocasiones con tallas someras y vértices sin definir. Algo diferente se observa en la puerta septentrional, de la que se conserva sólo una jamba resuelta con sillares de buena talla que presentan una anathyrosis con listeles de entre 5 y $8 \mathrm{~cm}$ (Asensio 2006: 148-149). Esta técnica de talla es eminentemente itálica y parece extenderse por el interior peninsular tras la fundación de Tarraco y la deductio de Valentia, acabada la guerra celtibérica del 133 a.C. (Asensio 2006: 153). Esto confirmaría la propuesta de los directores de la intervención arqueológica para los que esta puerta es posterior a la construcción de la muralla (Mena et al. 1988: 184-185).

\section{¿Y las torres?}

Llegados a este punto llama poderosamente la atención la ausencia de torres y otras obras de flanqueo a lo largo del recorrido de todo el perímetro defensivo (Fig. 2). En el lienzo externo de la denominada puerta norte (Fig. 3, punto 2) un leve retranqueo de pocos centímetros permitió afirmar la presencia de una torre jalonando la puerta (Gras et al. 1984: 55). En realidad dicho retranqueo responde al derrumbe del lienzo (Fig. 10), sin que hayamos podido reconocer elementos formales que permitan afirmar la presencia de una torre en este punto.

Recientemente concluimos que las torres que jalonaban las murallas se reducen consi- derablemente hasta casi desaparecer en los sistemas defensivos del valle medio del Ebro a partir de la segunda mitad del siglo III a.C. (Romeo y Royo 2015: 350-351). El análisis del trazado de sistemas defensivos celtibéricos de cronología similar proporciona los mismos resultados: mientras que el estudio de la fotografía aérea de ciudades celtibéricas como Valdeherrera, Segeda, Numancia o Arcobriga, entre otras, no permite reconocer torres, bastiones $\mathrm{u}$ otras obras de flanqueo hacia el exterior, en otras, como Contrebia Leukade, se ha podido constatar la presencia de torres proyectadas hacia el interior (Hernández 2007: 42-43).

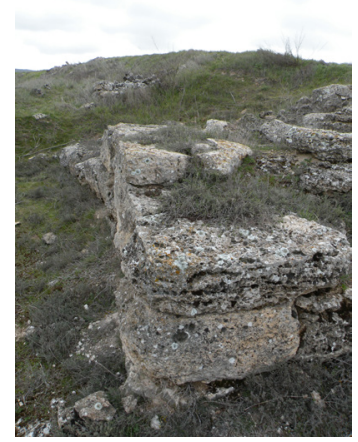

Figura 10. Aspecto actual de la esquina de la entrada norte.

La explicación a este fenómeno tiene que residir en un cambio sustancial en la defensa de los asentamientos de finales del siglo III y comienzos del II a.C. La torres permiten la defensa contra a un enemigo situado en las proximidades de la muralla, atacándolo desde los flancos. La ausencia de estas torres puede responder a tácticas basadas en la utilización de armas de mayor alcance que mantienen 
al enemigo a distancia, consiguiendo de este modo que las obras de flanqueo pierdan buena parte de su eficacia. Con este presupuesto táctico se hace imprescindible la potenciación de sistemas exteriores de defensa, situación que parece confirmarse en el caso que nos ocupa. No deja de ser revelador que los campamentos romanos de cronología republicana tampoco proyecten obras al exterior, sino que las torres se desarrollen hacia el interior creando una mayor superficie de defensa en altura para emplazar la artillería o el armamento de mayor alcance (Morillo 2003 y Morillo 2008: 77-79).

En resumen, podemos definir el sistema defensivo de Contrebia Carbica como sofisticado, correspondiendo con mucha probabilidad al último conflicto bélico que supuso la destrucción y rápida decadencia de la ciudad.

\section{Las alineaciones del recinto meridional}

Cuando estudiamos las fotografías aéreas del yacimiento de Villas Viejas apreciamos unas alineaciones en el recinto sur en la fotografía publicada en 1984 que parecía dibujar una trama ortogonal regular (Fig. 6). En un primer momento consideramos que estas alineaciones podrían ser resultado de los trabajos agrícolas, pero el hecho de que discurran en ocasiones en sentido perpendicular al de los surcos agrícolas parece refutar esa posibilidad (Boismier 1977, en el mismo sentido, Torres 2013: 505). Las líneas principales forman una retícula ortogonal con una tendencia modular (Fig. 11) sobre una unidad de 35 metros: un actus romano de 120 pies. Esto nos permite especular con la posibilidad, por supuesto pendiente de comprobación arqueológica, de la existencia de una trama urbana ortogonal en esta zona, ordenada en base al módulo del actus romano.

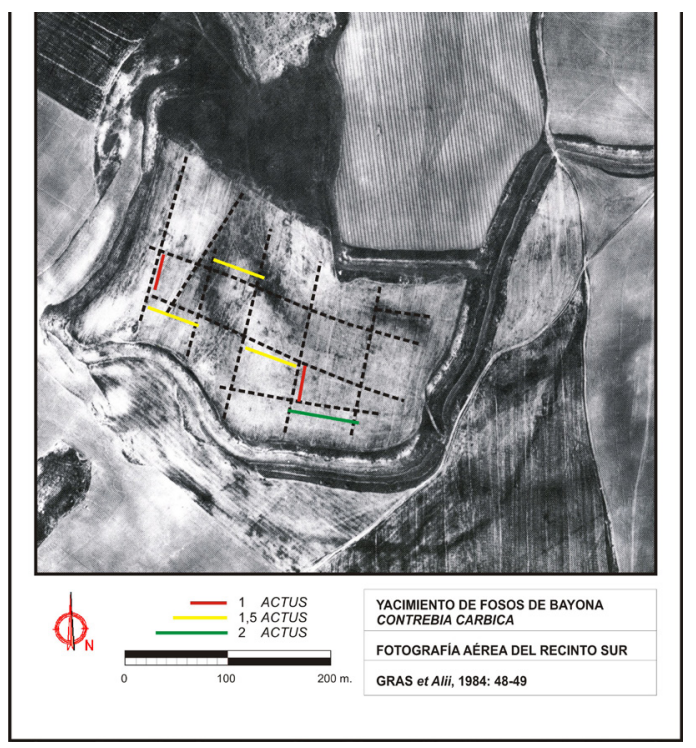

Figura 11. Fotografía aérea del recinto sur, indicando la trama visible.

Las fundaciones romanas republicanas ex nouo suelen organizarse en tramas urbanas ordenadas sobre la base del actus (Castagnoli 1971: 96-112) aunque en la Península Ibérica también las encontramos en ciudades a priori indígenas (Pina 2003, 2011: 47-48). Algunos de estos asentamientos en el valle del Ebro fueron denominados como ciudades en llano y se consideraron fundados por indígenas tras la segunda guerra celtibérica con una traza y urbanismo ortogonal que se aleja radicalmente de los patrones de asentamiento prerromanos (Burillo 2007: 313). Igualmente se ha consi- derado que se trata de ciudades de origen romano (Asensio 1994; Ezquerra 2005), con soluciones edilicias y decorativas inequívocamente itálicas, aunque con un horizonte material abrumadoramente indígena asociado en ocasiones, como en La Caridad de Caminreal, con elementos militares tan romanos como un scorpio (Vicente et al. 1997).

Esta casuística se amplía con la aparición en ciudades indígenas preexistentes de áreas que presentan esta planificación urbanística itálica. Este parece ser el caso que nos ocupa de Contrebia Carbica, y quizás los del yaci- 
miento de Valdeherrera, en Calatayud y La Corona, en Fuentes de Ebro, ambos en la provincia de Zaragoza. En Valdeherrera aparece una amplia zona ocupada con una trama ortogonal en la que se han exhumado cuatro insulae que responden al módulo de un actus (Sáenz y Martín-Bueno 2015: 89-106), con estancias dotadas de programas decorativos tan romanos como un techo pintado con casetones. En La Corona de Fuentes de Ebro se pudo reconocer una expansión en llano con trama ortogonal a partir de un núcleo anterior, asentado sobre una elevación (Ferreruela y García 1991).

Sin entrar a valorar y discutir en profundidad este fenómeno (Pina 2011, Asensio 2003), nos quedaremos con la posibilidad de estar en Contrebia Carbica ante una zona que responde a un modelo urbano similar al de los asentamientos ex nouo de la segunda mitad del II a.C., basados en modelos y planteamientos netamente itálicos y que nos está indicando la asunción por parte de la sociedad celtibérica de un urbanismo foráneo y, por lo tanto, de unas estructuras sociales y económicas diferentes a las de los siglos anteriores. Este hecho hace que valoremos la posibilidad, siempre pendiente de confirmación arqueológica, de una ampliación de Contrebia Carbica en la segunda mitad del siglo II a.C., quizás a partir del 133 a.C. debido a la presencia de sillares con anathyrosis en la puerta del norte (vid. supra), un momento en el que se reformaría la ciudad, abriendo nuevos accesos como la puerta norte, y quizás se urbanizaría toda una nueva zona al sur.

\section{Análisis táctico y estratégico del sistema defensivo}

La guerra era consustancial a la cultura celtibérica, uno de los principales elementos que la conforma y caracteriza (Lorrio 2016: 231). Por ello no debe extrañar que poseyesen la suficiente capacidad técnica y táctica como para planificar, construir y utilizar sistemas defensivos complejos, concebidos para hacer frente a los ejércitos más modernos del momento y proporcionados al tipo de ataque que se esperaba. Los sistemas defensivos se desarrollarán al mismo tiempo que la estrategia, la táctica, la logística y la tecnología militar, procurando ir por delante de los medios ofensivos (Quesada 2003: 69).

Para acometer el estudio estratégico y táctico del sistema defensivo que nos ocupa re- sulta imprescindible acotar estos términos, que en ocasiones se utilizan de forma errónea o indiscriminada. Consideramos acertada la definición del general francés André Beaufre, quien precisa que “(...) estrategia es el arte de hacer que la fuerza concurra para alcanzar las metas de la política. (...) La táctica es muy claramente el arte de emplear las armas en el combate para conseguir su mejor rendimiento". (Beaufre 1965: 12). De este modo, la estrategia de un sistema defensivo remite a las razones últimas de su construcción. Es un concepto holístico, en el que las defensas de una ciudad son un elemento más dentro de la planificación previa de un conflicto mucho más amplio. La táctica, como afirma el general francés, redunda en la eficacia en combate directo.

\section{La táctica}

Para analizar tácticamente este sistema defensivo hemos partido de su morfología junto con los alcances de dos tipos de arma utilizados masivamente en los asedios: los proyectiles de honda y los arcos (Fig. 12). Mientras que los proyectiles de honda poseen unos alcances medios entre 80 y 120 m (Romeo 2017) los arcos poseen alcances de rangos máximos de 200 metros (Quesada 2008: 122). La altura de las defensas juega un importante papel dado el marcado recorrido parabólico de los proyectiles (Skov 2013: 76). Con esto hemos calculado los alcances medios desde las defensas de la ciudad, localizando los puntos débiles de las defensas (Fig. 13). Es el flanco este de la ciudad el más débil y, por lo tanto, el que cuenta con una mayor concentración de recursos defensivos. La secuencia de muralla, antemuro y fosos crea una barrera formidable que aleja a la ciudad del alcance de las armas arrojadizas y los proyectiles de honda, aunque no del arco o de la artillería de torsión. El alcance de la artillería de torsión varía radicalmente dependiendo del tipo de maquinaria concreta utilizada. Autores como Marsden proponen alcances para pila catapultaria de $300 \mathrm{~m}$ (Marsden 1969: 47; Harmand 1976: 224), aunque el alcance de los bolaños de piedra sería sustancialmente menor tal y como puede deducirse del dato proporcionado por Filón de Bizancio en el libro V, 69, de su Sintaxis mecánica (Garlan 1974: 284) cuando propone la realización de campos fortificados de un estadio de anchura, unos $165 \mathrm{~m}$, para defenderse de la artillería. 


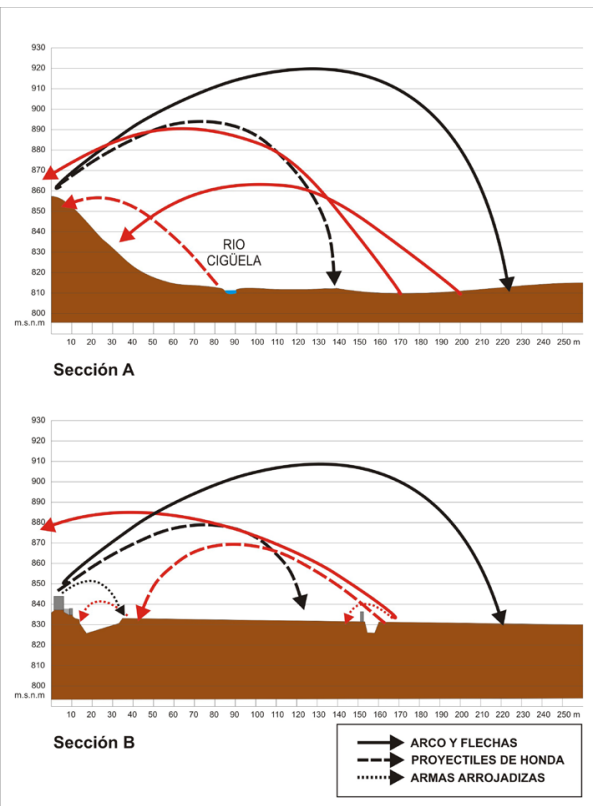

Figura 12. Alcances de proyectiles en dos secciones del yacimiento indicadas en la figura 13.

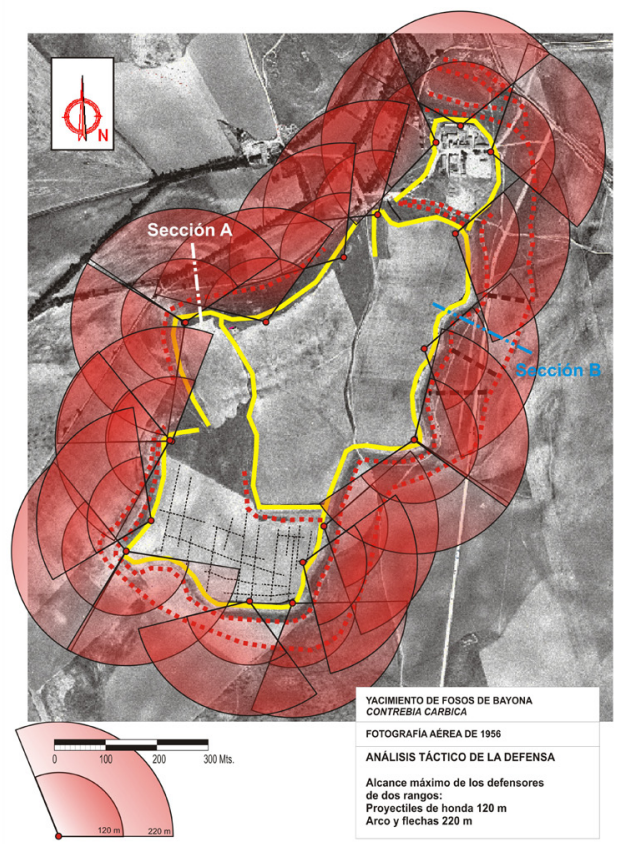

Figura 13. Análisis táctico de la defensa.

La distancia creada por la ubicación del foso exterior puede responder a la necesidad de defender la ciudad de ataques con proyectiles de honda, pero un solo foso, a 80 o $120 \mathrm{~m}$, es absolutamente ineficaz y un grave error táctico; necesariamente debía estar asociado con otros elementos defensivos que impidiesen el avance franco del enemigo, en caso contrario el foso se convierte en una trinchera para los atacantes. La total ausencia por el momento de excavaciones arqueológicas sobre estos nove- dosos elementos, tan alejados de los núcleos urbanos, impide que contemos con datos y detalles de primera mano de este tipo de defensas pero hay que pensar en la necesaria presencia de estructuras defensivas asociadas, como un agger, muro o empalizada que lograse detener a los atacantes. En este sentido, hay que recordar las evidencias de una empalizada de madera en el exterior del foso que defendía el yacimiento arqueológico del Cabezo de la Cruz en la Muela, Zaragoza, en un momento tan 
temprano como el siglo VII a.C. o los indicios de la presencia de una empalizada en Monte Bernorio (Torres et al. 2014: 120).

Otra posibilidad a valorar sería que este foso exterior corresponda realmente a obras realizadas por un eventual atacante, buscando aislar al enemigo encerrado dentro de la ciudad e impidiendo su huida, como en el famoso caso numantino. En el caso que nos ocupa los paralelos existentes y la existencia de fosos transversales que compartimentan el campo defensivo parece desaconsejar esta interpretación.

La segmentación del campo fortificado en tramos con la disposición de fosos transversales (Fig. 7) es una auténtica innovación dentro del panorama peninsular y parece encaminada, como ya hemos comentado, a segmentar el ataque y facilitar así la defensa (vid. supra). Es pronto para poder afirmar o desmentir nada en relación al origen y desarrollo de esta solución de barreras o fosos transversales en las defensas exteriores, aunque resultan sumamente interesantes los grandes paralelismos entre los tres casos en los que los hemos podido reconocer soluciones similares: Valdeherrera, Aratis y Contrebia Carbica. En estas ciudades el conjunto del sistema defensivo parecen corresponder a un momento, al menos de fines del siglo II o comienzos del I a.C., en los tres casos hay varios recintos defensivos, y los tres poseen destrucciones de cronología sertoriana (Saénz y Martin-Bueno 2015: 133, Fatás et al. 2015: $31)$. En buena lógica hay que pensar que estas defensas transversales corresponden al último episodio bélico que sufrió la ciudad ya que las fortificaciones nos suelen ofrecer una foto fija del final del asentamiento, por lo que en Contrebia Carbica estos fosos transversales responderían al contexto de la guerra de Sertorio.

El flanco oeste parece estar defendido por esta misma secuencia de dos fosos, aunque el gran desnivel existente, de más de $50 \mathrm{~m}$, hace que sea el flanco menos vulnerable. El desarrollo parabólico de los proyectiles y armas arrojadizas permite que la altura de las defensas amplíe el alcance de las armas de los defensores en la misma medida que reduce el alcance de las de los atacantes (Figs. 12 y 13). Al norte y al sur encontramos la misma secuencia defensiva, algo más potente al norte, donde parece que los fosos se abren hasta superar los veinte metros de anchura.

Finalmente, la misma concepción alveolar de la ciudad multiplica su potencial defensivo.
En caso de la toma de un recinto la existencia de fosos y murallas interiores permite aislarse y concentrar las defensas, un programa desarrollado para resistir a cualquier precio, algo que parece entrar en contradicción con la defensa de un contingente civil, que obliga a rápidas capitulaciones en el momento de caer una parte de las defensas.

Los sistemas defensivos desarrollados buscan forzar al enemigo a una táctica ofensiva concreta, para la cual el defensor ya se ha anticipado. Este sistema defensivo está desarrollado para defenderse de un contingente numeroso y bien armado, dotado de armas de largo alcance, intentando desplazar su ataque al flanco Este donde habían preparado una serie de dispositivos par segmentar el ataque, fragmentando y aislando al ejército enemigo. Parece que sin éxito.

\section{La estrategia}

Uno de los principios militares en las guerras de movimientos ha sido siempre el evitar por todos los medios los asedios, ya que suponen ralentizar el avance en campaña del ejército, inmovilizando una parte importante del mismo y causando un desgaste en tiempo, medios, provisiones y vidas.

En este sentido, los sistemas defensivos pretenden hacer desistir al enemigo del ataque a la ciudad, buscando que pasase de largo y que renuncie al asedio. Esto ha sucedido desde la antigüedad hasta la segunda guerra mundial, donde fue uno de los principios de la guerra relámpago alemana o Blitzkrieg. El General Guderian desarrollo su célebre estrategia basándose en el concepto del Schwerpunkt o punto focal donde concentrar las fuerzas móviles para romper el frente y conseguir así ventaja al luchar en la retaguardia del enemigo. Se creaban de este modo bolsas de resistencia enemiga que se dejaban atrás para ser reducidas por la infantería (Guderian 2002).

En las fechas que nos ocupan con toda seguridad no se escatimarían medios para preparar las defensas de ciudades importantes y con alto valor estratégico en el contexto de conflictos bélicos generalizados; se trata de circunstancias excepcionales en las que la vida de una comunidad está en peligro, por lo que ésta pondrá todos sus recursos y medios técnicos y humanos para la defensa del asentamiento. Se sanearían y potenciarían las defensas, se limpiarían los fosos y se eliminarían los elemen- 
tos y estructuras que supusiesen una desventaja táctica, incluso destruyendo y terraplenando zonas urbanas fuera de las murallas, un recurso que aparece citado por los tratadistas clásicos (Aen tact. II.2) y que busca impedir que los atacantes encuentren resguardo y se atrincheren en las inmediaciones de las murallas de la ciudad.

En el caso de Contrebia Carbica podemos considerar que estamos frente a una ciudad que no solo jerarquiza un territorio, sino que además posee un impresionante sistema defensivo y una situación privilegiada que permite controlar una vía de penetración hacia el interior de Celtiberia, como veremos más adelante.

\section{5. ¿Non bis idem?}

El sistema defensivo de Contrebia Carbica y su urbanismo parecen definir un modelo personal y propio, pero buscando paralelos encontramos yacimientos que poseen varias de estas características en cronologías similares a las que nos ocupan.

Este es sin duda el caso de Valdeherrera, una ciudad que muestra grandes similitudes con Contrebia Carbica. Este yacimiento se extiende a lo largo de más de un kilómetro de longitud con una extensión de 45 Ha (Sáenz y Martín-Bueno 2015: 75). Se articula en dos grandes espacios o recintos diferenciados. Los resultados de una reciente intervención en el recinto norte parecen indicar una ocupación coetánea de ambos espacios (Saénz y Martín-Bueno 2015: 111). Una muralla sin ningún tipo de obra de flanqueamiento recorre todo el yacimiento. Las prospecciones magnéticas han permitido reconocer que ésta se encuentra formada por dos lienzos paralelos creando una anchura total superior a los tres metros (Martín-Bueno et al. 2009: 431). La puerta sur está conformada por sillares que presentan una clara anathyrosis, al igual que la puerta septentrional de Contrebia Cárbica. El foso recorre buena parte del yacimiento y posee unas considerables dimensiones (Saénz y Martín-Bueno 2015: 76, fig. 86). Al oeste recorre el kilómetro de longitud de la ciudad, mientras que al sur supera los $300 \mathrm{~m}$ de recorrido. Se reconocen diferentes anchuras en distintos tramos, pudiendo existir un foso doble en la zona suroeste, creando una distancia defensiva de $136 \mathrm{~m}$. El análisis que hemos realizado sobre la fotografía antigua disponible, especialmente el vuelo de 1956, permite apuntar la posibilidad de que este foso doble discurriría a lo largo de la totalidad de ambos flancos, apareciendo actualmente el foso exterior intensamente desdibujado por la intensa presión antrópica en esta zona. Como se ve, los paralelos con nuestra Contrebia son notables. Más aún cuando en el segundo recinto aparece una zona urbanizada con edificios construidos ex nouo a mediados del siglo II a.C. con un nivel de destrucción situado en el contexto del conflicto sertoriano (Saénz y Martín Bueno 2015: 97).

Una extensión igualmente enorme parece tener el yacimiento que se ha identificado como Segontia Lanka en el cerro de la cuesta del Moro, a dos kilómetros de Langa de Duero en Soria. Se han podido identificar dos recintos defensivos que abarcan una superficie próxima a las $60 \mathrm{Ha}$ (Tabernero et al. 2005: 197). Las campañas de excavación realizadas sobre esta ciudad han reconocido líneas de muralla con grosores medios de $2,5 \mathrm{~m}$, formadas por dos paramentos con un relleno interior (Jimeno 2011: 241). No se han podido identificar torres ni obras defensivas. Estos dos recintos poseen una ocupación sincrónica y la cultura material permite afirmar la aparición de esta gran ciudad de los arévacos en un momento difuso de la segunda mitad del siglo II a.C., tras el fin de la segunda guerra celtibérica (Jimeno 2011: 266). La destrucción de esta ciudad se sitúa en las guerras sertorianas.

Dimensiones similares, con $60 \mathrm{Ha}$, tendría la Clunia celtibérica en Los Castrillos, Peñalba de Castro, a $1200 \mathrm{~m}$ al este de la Clunia romana (Sacristán 2005: 183). De esta ciudad arévaca, únicamente se ha podido constatar la presencia de largos tramos de muros defensivos y una cultura material que sitúa su origen a finales del siglo III o comienzos del II a.C. y un final, nuevamente, en el contexto del conflicto provocado por Sertorio (Jimeno 2011: 241).

Segeda posee igualmente unas dimensiones próximas a las $42 \mathrm{Ha}$ (Burillo 2005: 149), extensión que responde al trazado hipotético de muralla perimetral que se ha localizado en unos pocos tramos con una anchura irregular de 4 m (Burillo 2006: 232, fig. 39). En ningún punto se ha podido documentar la existencia de obras de flanqueo ni de fosos o sistemas defensivos desarrollados.

Numancia, pese a que con sus $9 \mathrm{Ha}$ (Jimeno 2005: 162) parece quedar tras las grandes superficies que estamos viendo, posee rasgos comunes con el patrón que comienza a dibujar- 
se, ya que la muralla posee una anchura entre 3,5 y $5,9 \mathrm{~m}$, con tirantes o perpiaños (Jimeno 2011: 238).

El yacimiento de Castejón I o El Romeral de Aranda de Moncayo, identificado como la ciudad de Aratis (Fatás et al., 2014: 19-21), cuenta con unas 11 Ha de extensión, y dos recintos defensivos. Se ha podido reconocer una primera ocupación defendida por murallas con torres rectangulares cuya cronología se puede situar en el siglo V o IV a.C. Envolviendo este primer recinto aparece una ampliación de finales del III o comienzos del II a.C. defendida por lienzos de muralla continuos, sin obras de flanqueamiento, y una secuencia de tres fosos que crean un perímetro defensivo de $90 \mathrm{~m}$ (Fatás et al. 2014: 24-33).

Contrebia Leukade tampoco destaca por su extensión, con 12 Ha (Hernández, 2005: 129). Posee un lienzo defensivo continuo de cronología celtibérica, donde se ha excavado una secuencia de tres torres, de hasta $70 \mathrm{~m} 2$ de superficie, proyectadas hacia el interior y que el director de las excavaciones considera de influencia mediterránea (Hernández 2007: 42). La cronología propuesta para este sistema defensivo es del siglo III a.C. (Hernández 2007: 43).

En conclusión, y tras este rápido repaso, podemos ver que existen elementos morfológicos en común entre varias ciudades celtibéricas de finales del siglo III y de la primera mitad del II a.C., tantos que quizás no sean el resultado de acontecimientos o fenómenos individuales o aislados; hay que valorar la posibilidad de que se trate de la respuesta a fenómenos comunes en toda Celtiberia y sus zonas limítrofes, un fenómeno que necesariamente debe ser la amenaza de Cartago primero y de Roma inmediatamente después..

\section{Contrebia Carbica y su contexto histórico}

Tras la segunda guerra púnica Roma controlaba la costa mediterránea de la Península Ibérica penetrando hacia el interior por valles fluviales como el del Ebro, el Júcar o el Turia (Pérez Blasco 2014: 467). La organización del territorio y la división de la península en dos provinciae, Hispania Citerior e Hispania Ulterior, con su consiguiente repercusión sobre el control sobre los recursos económicos provocó el levantamiento de varios pueblos ibéricos a comienzos del siglo II a.C. (Pina 2006: 71-74,
Pérez 2014: 161-163), lo que supuso la llegada del cónsul Marco Porcio Catón el 195 a.C. para reprimir la revuelta (Liv., XXXIV, 20; App., Hisp., 41; Cass. Dio., XVIII, 60; Flor., I 33,9$)$ y el objetivo, quizás más relevante, de tomar contacto con la zona interior de la Península Ibérica, desconocida por la República en ese momento (García Riaza 2006: 82-86; Pina 2011: 41-42). Catón desembarcó en Emporion, un emplazamiento seguro, y marchó hacia el sur por la costa levantina hasta el Guadalquivir, volviendo hacia Celtiberia por el interior de la Península (Knapp 1977, 1980), quizás hasta la misma Numancia (Pina 2006: 73), para bajar por el Ebro hacia el Mediterráneo. Recientemente se ha barajado la posibilidad de que el itinerario del cónsul de la República respondiese igualmente a la necesidad de controlar la expansión de los pueblos celtibéricos hacia el sur (Pérez 2014: 162), lo que supondría un evidente interés y un conocimiento de las relaciones internas y los movimientos de los distintos populi existentes en la península Ibérica por parte de Roma. Tras la incursión de Catón las fuentes nos relatan continuos conflictos, entre los que queremos destacar las actividades romanas y celtibéricas en relación a una posible línea fronteriza o de demarcación en el río Tajo.

La importancia de esta línea transversal en la Península Ibérica se había puesto ya de manifiesto en el ataque a Aníbal por parte de una coalición de vacceos, carpetanos y olcades cuando el general cartaginés vadeaba el rio (Pérez 2014: 162), o por la derrota poco después de una coalición de celtiberos, vacceos y vettones en las inmediaciones de Toletum, en un vado del río (Liv., XXXV, 7). El 185 las fuerzas conjuntas de Calpurnio Pison y Quinctio Crispino vuelven a derrotar, en un punto próximo a un vado de Tajo, quizás el mismo, a una coalición de carpetanos y celtíberos (Liv. XXXIX, 30-31; XLII, 2-3. Fig. 14). Esta derrota haría vulnerable desde este mismo momento el flanco sur de Celtiberia (García Riaza 2006: 86) y parece señalar al Tajo como límite meridional de Celtiberia o al menos de su zona de influencia directa (Sánchez et al. 2015: 71). No obstante, el registro arqueológico parece indicar que el ámbito meridional celtibérico quedaba entre la misma Contrebia Carbica y las fuentes del Turia (Lorrio 2007: 233-239, figs. 2 y 3).

En este contexto es muy sugerente la posibilidad de relacionar la aparición de nuestra 
ciudad con la necesidad de controlar una vía de comunicación de Celtiberia con el litoral sur y sureste (Sánchez et al. 2015: 71). Esta posibilidad cobra más peso si consideramos la íntima relación que comienza a establecerse entre la aparición de nuevas ciudades celtibéricas y las sucesivas líneas de frontera delimitadas por el avance efectivo de Roma (Jimeno 2011: 233). Poco a poco parece que toma cuerpo en la investigación la existencia de "cierta noción de territorialidad celtibérica" que parece propiciar un perímetro defensivo desde finales del siglo III (Sánchez et al. 2015: 70). Contrebia Carbi$c a$ se encuentra en una zona claramente fronteriza (Gozalbes 2000: 146), controlando una vía de acceso desde el interior hacia el corazón de Celtiberia (Fig. 14) y tiene mucho sentido su aparición tras la segunda guerra púnica, en un momento de definición por oposición a otra potencia, llegada para quedarse.

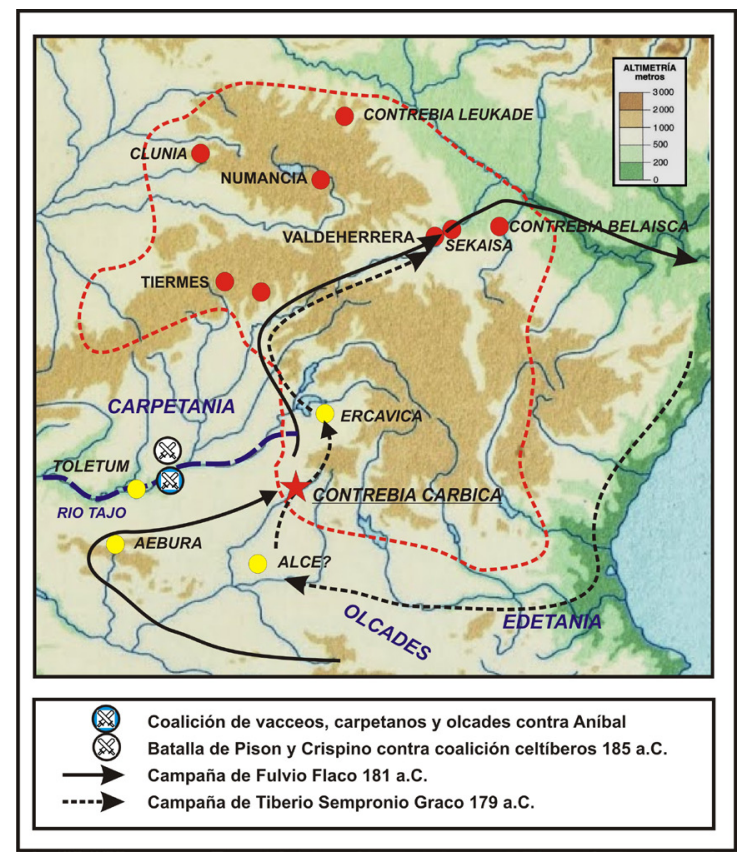

Figura 14. Campañas de Fulvio Flaco y Tiberio Sempronio Graco

El 182 a.C. la República elige como pretor para la Hispania Citerior a Quinto Fulvio Flaco quien se enfrentaría a una gran coalición de celtíberos, un ejército de 35.000 combatientes (Pérez 2014: 165 y García Riaza 2006: 87). Este ejército sería derrotado por el pretor el 181 cerca de la ciudad de Aebura, que se sitúa en Carpetania. Resulta muy interesante la cita de Livio (XL, 30) al describir el ejército celtibérico como perfectamente ordenado en orden cerrado de combate o acies instructa, organizado por estandartes y con la retaguardia protegida por un campamento defendido por una reserva de 5000 hombres. Como venimos subrayando, la cita del patavino demuestra que el ejército celtibérico en un momento tan temprano como el 181 a.C. es un ejército moderno, desarrollado y preparado para el combate en los términos habituales de las grandes potencias mediterráneas.

Tras esta gran batalla Diodoro (XXIX, 28) y Apiano (Iber. 42) comentan que Fulvio Flaco somete a la recién fundada Complega, ciudad que si bien se ha situado en el valle del Ebro (Sánchez et al. 2015: 73), se tiende a identificar igualmente con Contebia Carbica, interpretación apoyada en Livio XL, 33 (Lorrio, 2012a: 249, García Riaza 2006: 87).

El relato de Livio resulta especialmente interesante. Para las murallas de la Contrebia tomada por el pretor utiliza el término moenia, un término que se utiliza para describir las murallas urbanas de carácter monumental (Gros 1992: 211-212; Romeo 2005: 203), una monumentalidad que por otra parte no cuesta reconocer en el sistema defensivo que hemos descrito para el yacimiento conquense.

Apiano, por su parte, precisa que Complega era una ciudad recién edificada y fortificada, que había crecido rápidamente. Algunos autores postulan que quizás la ciudad había surgido para acoger a posibles iberos fugitivos del ejército romano y lusones derrotados por el pretor 
(Jimeno 2011: 233), o a consecuencia de un fenómeno de sinecismo (Lorrio 2012a: 249). El relato de Apiano difiere sensiblemente del de Livio. La fecha en la que escribe el alejandrino puede ser la causa de algunos errores de bulto, como considerar a Flaco cónsul, pero el encuadre de los acontecimientos parece correcto; la batalla de Aebura parece ser la mencionada en el texto y Complega puede ser la Contrebia de Livio. En esta ciudad se concentran los iberos derrotados en la batalla para preparar un ataque desde la misma. Estos iberos, y probablemente también celtíberos dado el discurso de Apiano y la mención explícita a los lusones, eran gente desprovista de tierra, algo relevante dado que el alejandrino lo menciona dos veces. La precisión de que eran antiguos aliados huidos del ejército romano puede indicarnos que se trataba de mercenarios: iberos sin tierra $y$ de vida errante. En cualquier caso se refugian para preparar una rápida respuesta en esta ciudad, recién fundada y fortificada y que había crecido muy rápidamente. Esta precisión parece sugerir que la razón de la fundación de la ciudad, que habría que situar ente el 190 y el 181 a.C. si hacemos caso a Apiano, proviene de razones estratégicas relacionadas con el contexto bélico de estos años, que no es otro que la guerra contra Roma.

De ser cierta la interpretación de Jimeno tendríamos un relato de primera magnitud sobre la fundación de nuestra ciudad que, por otra parte, concordaría perfectamente tanto con los datos arqueológicos como por esa noción de perímetro defensivo celtibérico (Sánchez et al.
2015: 70). Sería ésta una situación que de confirmarse solo podríamos definir como excepcional dentro del panorama del conocimiento que poseemos de Celtiberia. Del mismo modo, los combates producidos en un vado del Tajo, no demasiado lejano, y la penetración de Flaco da razón a la importancia estratégica de esta zona, lo que nos lleva a concluir que tanto los celtíberos como los comandantes romanos sabían que ésta era una vía vulnerable para atacar la yugular de Celtiberia. Así parece corroborarlo la estrategia desplegada posteriormente por Lucio Postumio Albino y Tiberio Sempronio Graco, que relevaron a Flaco el 179 a.C. (Liv., XL, 47, 1-2).

Nada sabemos con certeza de Contrebia Carbica tras las menciones de la campaña de Flaco el 181 a.C, ni en las fuentes ni en el registro arqueológico dado que la ciudad se rindió y no se comenta ninguna punición del pretor sobre la misma. El estudio del material de superficie junto a los resultados estratigráficos hacen que no podamos precisar nada nada más allá que el momento de la destrucción de la ciudad, que se ha relacionado sin duda con el conflicto sertoriano (vid. supra).

Repasados los acontecimientos de este episodio bélico, en cuyo relato no vamos a entrar por motivos obvios, debemos quedarnos con la cita de Estrabón III, 4, 13, que afirma que Sertorio y Metelo combatieron cerca de Segobriga y Bilbilis. En efecto, el 74 a.C. el veterano general, tras invernar en la Narbonense y recibir dos legiones llegadas de Italia se encamina hacia el rio Ebro para descender por la vía del río Jalón hasta Car-

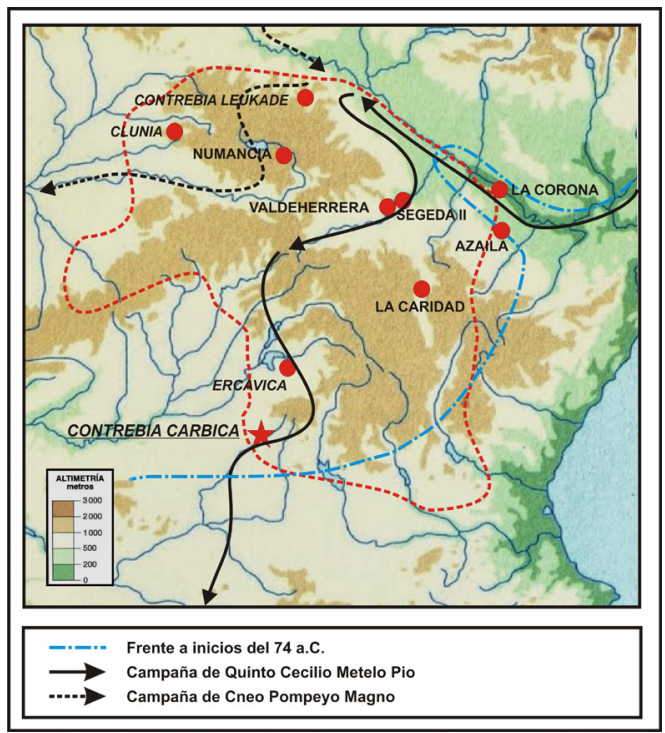

Figura 15. Campaña de Quinto Cecilio Metelo Pio. 
petania (García Morá 1991: 318), destruyendo a su paso ciudades como la de Valdeherrera (Sáenz y Martín Bueno 2015: 129). Podemos situar en este contexto la destrucción de Contrebia Carbica ya que la referencia a Segobriga es lo suficientemente concreta (Fig. 15).

La guerra de Sertorio fue diferente a las guerras convencionales de grandes movimientos, ya que su política de acuerdos y apoyos con ciudades y pueblos indígenas provocó una guerra de posiciones en la que los avances no podían dejar ciudades sin someter en la retaguardia (Romeo 2006: 49). Esto supuso la destrucción de gran parte de los centros urbanos del valle medio del Ebro. Se documentan patrones similares de destrucción y abandono con cronología sertoriana en Contrebia Belais$c a$, en la Caridad, en la Cabañeta (Ferreruela y Minguez 2006: 331), en la Corona (Mínguez y Ferreruela 2012: 267-270), en el Cabezo de Alcalá de Azaila (Beltrán 2013: 481-490), en Segeda II (Franganillo 2015: 385) y en el yacimiento ya comentado de Valdeherrera. En este contexto es muy posible que la destrucción localizada en Fosos de Bayona corresponda al ejército de Metelo, cuyo paso por la comarca quedaría atestiguado por el tesorillo de Abia de la Obispalia, en Cuenca, con 34 denarios de Bolskan y 2 de Contrebia Carbica (Arévalo 2008: 144)

Tras la destrucción o durante el conflicto sertoriano, la ciudad de Contrebia Carbica iría marchitándose rápidamente en favor el emergente núcleo de Segobriga hasta desaparecer totalmente a mediados del siglo I a.C.

\section{Conclusiones}

Hemos podido ver el potencial del sistema defensivo de Contrebia Carbica. Es un sistema complejo y evolucionado, cuya imagen final, la que nos ha llegado, es sin duda una foto fija de los acontecimientos que supusieron la destrucción y el final de la ciudad. No obstante los parámetros básicos del sistema defensivo, así como su misma concepción urbanística alveolar debe pertenecer necesariamente al momento de su aparición, a finales del siglo III o más probablemente a comienzos del II a.C.

Ante esta cronología proporcionada por la cultura material, resulta sumamente sugerente la posibilidad de que esta ciudad sea la Contrebia que nos comenta Livio o la Complega de Apiano. La ciudad aparecería de este modo respondiendo a la necesidad del control y defensa de una vía de penetración hacia el interior de Celtiberia dentro de una estrategia de defensa contra Roma, existiendo elementos similares en yacimientos indígenas de grandes dimensiones que parecen comenzar a definir una serie de patrones comunes.

La cronología similar de aparición de estos grandes asentamientos parece situar la razón de la aparición de estas ciudades tanto en un notable crecimiento demográfico como en el desarrollo de una estrategia de defensa de un territorio que quizás se extiende más allá del propio, tal y como sugieren las numerosas alianzas entre populi (vid. supra).

Estamos de acuerdo con Pina $(2011,50)$ cuando precisa que el mismo término Celtiberia es una creación romana, casi con toda seguridad ajena a los mismos populi que englobaba (Beltrán 2004), pero esta realidad no tiene por qué entrar en contradicción con la asunción de la inminencia de un peligro común para pueblos vecinos entre sí, sobre todo en un primer momento en el que las relaciones con Roma estaban por definirse y que podemos acotar en el fin de la primera guerra celtibérica, el 175 a.C. (García Riaza 2006: 92). Para cerrar este conflicto, Tiberio Sempronio Graco estableció una serie de sólidos pactos a cambio de recursos y tropas, prohibiendo la fortificación o creación de nuevas ciudades, algo que podría explicar la demora de reconstrucción de algunos yacimientos destruidos en la primera guerra púnica (Romeo 2016: 87), fundando Graccurris el 179/178 a.C., la primera ciudad romana del valle medio del Ebro y una de las primeras en la Península Ibérica, tras la temprana Italica, y estableciendo numerosas guarniciones para asegurar una pax que se prolongó más de veinte años.

Las condiciones ventajosas de este tratado supusieron la victoria de la estrategia romana de atomizar los populi al reducir la unidad organizativa a las civitates, fomentando así relaciones bilaterales de las mismas con Roma en detrimento de los vínculos y relaciones entre las distintas comunidades celtibéricas (García Riaza 2006: 91). El papel fundamental de esta Paz de Graco en la definición de una Celtiberia se pone de manifiesto en la narración de Polibio (XXXV, 2, 15) de los acontecimientos del 152, cuando el pretor M. Claudio Marcelo envía legados de los celtiberos en armas y de los fieles a Roma al Senado para dirimir sus disputas. Los arévacos, como enemigos deben 
acampar y esperar fuera del pomoerium y en su alegato asumen su error al sublevarse, aceptando el pago de la sanción correspondiente y exigiendo acogerse de nuevo al acuerdo suscrito con Roma en tiempos de Tiberio (Sempronio Graco).

Sin duda el papel jugado por las bases establecidas por la paz de Graco fue definitiva, propiciando un cambio radical de la mentalidad de los pueblos que vivían en esta zona peninsular, una metamorfosis en la que los mercatores y negotiatiores itálicos no fueron ajenos (García y Sánchez 2014: 444, Beltrán 2011: 144-147). Durante este período, del 178 al 153 a.C., las comunidades indígenas asumieron rápidamente sistemas de peso y medida, la cultura material, la escritura.

Quizás haya que pensar en la reproducción de los modelos urbanísticos itálicos en un mo- mento algo más tardío, tal y como parece indicar la probable coincidencia de la urbanización plenamente itálica del tercer recinto de Contrebia Carbica y la construcción de la monumental puerta septentrional, con una anathyrosis en los sillares que se llevan a fechas posteriores al 133 a.C. (vid. supra), lo que coincidiría con la fecha propuesta para la aparición de otras ciudades de trama similar, como La Caridad de Caminreal.

Con el tratado de Graco se había establecido una íntima relación que cambió radicalmente el sustrato cultural de un modo desigual pero irreversible. Pese a la segunda y tercera guerra celtibérica, Roma se había implantado de un modo definitivo en el día a día de estos pueblos, tanto que poco más de un siglo después ellos mismos se definían como celtiberi.

\section{Bibliografía}

Abascal, J.M.; Ripollés, P.P., (2000): Las monedas de Konterbia Karbika. En Olcina y Soler 2000: 13-75.

Almagro, A; Lorrio, A.J. (2006-2007): De Sego a Augusto: los orígenes celtibéricos de Segóbriga. Boletín del Seminario de Estudio de Arte y Arqueología, Arqueología, LXXII-LXXIII: 143-181.

Alonso, N.; Junyent, E.; Lafuente, A.; López J.B. (2003): Cheveaux-de-frise i fortificació en la primera edat del ferro europea (N. Alonso; E. Junyent: A. Lafuente; J.B. López, coords.) Universitat de Lleida.

Arévalo, A. (2008): Aprovisionamiento y circulación monetaria en la Meseta Sur durante la época romana. En Carrasco 2008: 127-183.

Asensio, J.A. (1994): Primeras manifestaciones del urbanismo romano-republicano en el valle medio del Ebro: una nueva interpretación sobre las ciudades en llano de planta ortogonal en Aragón de finales del s. II y comienzos del I A.E. Zephyrus, XLVIII: 219-255.

- (2003): Urbanismo romano republicano en la región de la cuenca del Ebro (Hispania Citerior): 179-44 a.C. Archivo Español de Arqueología, 76: 159-178

- (2006): El gran aparejo en piedra en la arquitectura de época romana republicana de la provincia Hispania Citerior: opus siliceum y opus quadratum. Salduie, 6: 117-161.

Badie, A.; Gailledrat, E.; Moret, P.; Rouillad, P.; Sánchez, M.J.; Sillières, P. (2000): Le site antique de La Picola à Santa Pola (Alicante, Espagne). Casa de Velázquez, Paris-Madrid.

Beaufe, A. (1965): Introducción a la estrategia. Instituto de estudios políticos. Madrid.

Belarte, M.C.; Benavente, J.A.; Fatás, L.; Diloli, J.; Moret, P.; Noguera, J. (2012): Iberos del Ebro. (Belarte, M.C.; Benavente, J.A.; Fatás, L.; Diloli, J.; Moret, P.; Noguera, J., eds.), Documenta 25. Institut Catalá d'Arqueologia Clásica. Tarragona.

Beltrán, F. (2004): Nos celtis genitos et ex hiberis. Apuntes sobre las identidades colectivas en Celtiberia. En Cruz y Mora, 2004: 87-145.

- (2011): ¿Firmas de artesano o sedes de asociaciones comerciales? A propósito de los epígrafes musivos de Caminreal (E.7.1), Andelo (K.28.1) y El Burgo de Ebro (HEp11, 2001, 621 = AE 2001, 1237). En Luján y García 2011: 139-147.

Beltrán, M. (2013): Azaila. Estado de la cuestión en 2013. Caesaraugusta 83.

Berrocal, L. (2004): La defensa de la comunidad: sobre las funciones emblemáticas de las murallas protohistóricas en le Península Ibérica. Gladius, XXIV: 27-98.

-; Barrera, J.L.; Caso, R.; Cabanillas, G.C. (2014): "Nertobriga Concordia Iulia. La conquête de la Béturie. En Cadiou y Caballero 2014: 273-297.

Boimier, W.A. (1997): Modelling the effects of tillage processes on artefacts distribution in the plough zone. A simulation study of tillage-induced pattern formation. British Arqueological Review British series 259 , Oxford. 
Burillo, F. (2005): Segeda. En Jimeno 2005: 145-152.

—, 2006: La ciudad estado de Segeda I, en Burillo 2006: 203-241.

-, 2006: Segeda y su contexto histórico. Entre Catón y Nobilior (195 al 153). (F. Burillo, ed.). Centro de estudios celtibéricos de Segeda. Mara, Zaragoza.

—, 2007: Los Celtiberos. Etnias y estados. Crítica, Barcelona.

-; Chorda, M. (2014): Nuevos hallazgos, nuevas interpretaciones. VII Simposio sobre Celtiberos. (F. Burillo; M. Chorda, eds.). Daroca, Zaragoza. Centro de estudios celtibéricos de Segeda. Mara, Zaragoza.

Caballos, A.; Lefebvre, S. (2011.): Roma generadora de Identidades. La experiencia Hispana. (A. Caballos; S. Lefebvre, coords.) Collection de la Casa de Velázquez, Volume 123, Casa de Velázquez y Universidad de Sevilla.

Cadiou, F.; Caballero, M. (2014): La guerre et ses traces. Conflits et sociétés en hispanie à l'époque de la conquête romaine (III ${ }^{e}-I^{e r}$ s. a.C.). (F. Cadiou, M. Caballero, coords.), Ausonius editions. Memoires 37. Bordeaux.

Campana, S.; Musson, C.; Palemer, R. (2005): In volo nel passato. Aerofotografia e cartografia archeologica. ( S. Campana; C. Musson; R. Palemer, eds.) Firenze.

Carrasco, G. (2007): Los pueblos prerromanos en Castilla - La Mancha, (G. Carrasco, coord.) Ediciones de la Universidad de Castilla - La Mancha, Cuenca.

- (2012): La ciudad romana en Castilla - La Mancha, (G. Carrasco, coord.) Ediciones de la Universidad de Castilla - La Mancha, Cuenca.

Castagnoli, F. (1971): Orthogonal Town Planning in Antiquity. Cambridge. Mass. London.

Cerdeño, M.L.; Chorda, M.; Gamo, E. (2014): Huellas arqueológicas de la conquista romana en Celtiberia: el oppidum de "Los Rodiles" (Guadalajara, España). En Cadiou y Caballero 2014: 297-317.

Cruz, G.; Mora, B. (2004): Identidades étnicas, identidades politicas en el mundo prerromano hispano (G. Cruz; B. Mora coord.), Ediciones de la Universidad de Málaga, Málaga.

Deroux, C. (1980): Sudies in Latin Literature an Roman History. (C. Deroux, ed.) Bruselas.

Ezquerra, B. (2005): La ciudad romana de La Caridad. En Jimeno 2005: 205-212.

Fatás, L.; Graells, R.; Lorrio, A.; Romeo, F. (2014): Dos nuevos cascos hispano-calcídicos en contexto urbano: los oppida celtibéricos de Aratis (Aranda de Moncayo, Zaragoza) y Contrebia Carbica (Villas Viejas, Cuenca). Boletín del Seminario de Estudio de Arte y Arqueología, Arqueología, LXXX: 13-51.

Ferreruela, A.; García, E. (1991): Informe preliminar sobre la excavación de urgencia realizada en La Corona (Fuentes de Ebro, Zaragoza). Arqueología Aragonesa, 1988-1989: 177-192.

-; Mínguez, J.A. (2006): Excavaciones en la ciudad romanorrepublicana de La Cabañeta (El Burgo de Ebro, Zaragoza): campañas de 2004 y 2005. Salduie, 6: 331-339.

Ferreruela, A.; Simón, M ${ }^{\text {a }}$ P. (1994): Informe sobre las prospecciones arqueológicas realizadas en los yacimientos de La Cabañeta, (Burgo de Ebro) y La Corona (Fuentes de Ebro), así como en sus áreas de influencia. Arqueología Aragonesa, 1994: 21-29.

Franganillo, D. (2015): Los sistemas defensivos de una ciudad celtibérica a finales de la II Edad del Hierro. El caso de Segeda II. En Rodríguez et al. 2015: 385-399.

García, F. (1991): Un episodio de la Hispania republicana: la guerra de Sertorio. Universidad de Granada, Granada.

- (2006): La expansión romana en Celtiberia. En Burillo 2006: 81-94.

-; Sánchez, E, (2014): ¿Del mercado al tratado?. El papel del comercio itálico en las relaciones celtibero-romanas anteriores a la provincialización. En Burillo y Chorda 2014: 435-444.

Garlan, Y. (1974): Recherches de poliorcétique grècque. Bibliotheque des Écoles Françaises d'Athenes et de Rome 223, Paris.

González, A. (2011): La Fonteta. Excavaciones de 1996-2002 en la colonia fenicia de la actual desembocadura del rio Segura (Guardamar de Segura, Alicante). Vol. 1, Alicante, Barcelona.

Gozalbes, E. (2000): Caput celtiberiae. La tierra de Cuenca en las fuentes clásicas. Ediciones de la Universidad de Castilla-La Mancha, Cuenca.

Graells, R.; Marzoli, D. (2016): Armas de la Hispania Prerromana. Actas del encuentro Armamento y arqueologías de la guerra en la Península Ibérica prerromana (s. VI-I a.C.): problemas, objetivos y estrategias. (R. Graells; D. Marzoli, eds.) RGZ - Tagungen Band 24.

Gras, R.; Mena, P.; Velasco, F. (1984): La ciudad de Fosos de Bayona (Cuenca). Inicios de la Romanización. Revista de Arqueología, 36: 48-57. 
Gros, P. (1992) : Moenia: aspects défensifs et aspects représentatifs des fortifications. En maele y Fossey $1992: 211-215$.

Guderian, H. (2002): Panzer Leader. De Capo Press, Nueva York.

Harmand, J. (1976): La guerre antique: de Sumer à Roma. Edaf, Paris.

Hernández, J.A. (2005): Contrebia Leukade. En Jimeno 2005: 129-136.

— 2007 : Contrebia Leukade. Guía arqueológica. Logroño, Gobierno de La Rioja.

Hernández, M.C. ; Cámara, M.E. ; Velasco, F. ; Mena, P. ; Gras, R. (1992): Aplicación de algunos métodos geofísicos (eléctrico, magnético y gravimétrico) en Fosos de Bayona (Huete, Cuenca). Jornadas sobre teledetección y geofísica aplicadas a la arqueología, Madrid, 1989, Ministerio de Cultura: 85-92.

Jimeno, A. (2005): Celtíberos. Tras la estela de Numancia. (A. Jimeno, ed.). Diputación de Soria, Soria

- (2011): Las ciudades celtibéricas de la Meseta Oriental. Complutum 22 (2): 223-276.

Jimeno, A; Revilla, M.L. Torre, J.I.; Chaín, A.; Liceras, R. (2017): Numancia, Garray (Soria). Guía arqueológica. Soria.

Knapp, R.C. (1977): Aspects of the Roman experience in Iberia, 200-106 B.C.. Universidad de Valladolid. Valladolid.

Knapp, R.C. (1980): Cato in Spain, 195/194 B.C.: Chronology and Geography. En Deroux 1980: 21-56.

Lawrence, A.W. (1979): Greek aims in fortifications. Oxford.

Lorrio, A.J. (2007): Celtíberos y bastetanos en el oriente de la Meseta Sur: Problemas de delimitación territorial. En Carrasco 2007: 226-270.

- (2012a): Procesos de continuidad y discontinuidad entre los oppida celtibéricos y las ciudades romanas en la Meseta Sur. Los casos de Segobriga y Ercavica. En Carrasco 2012: 225-285.

- (2012b): Fosos en los sistemas defensivos del levante ibérico (siglos VIII-II a.C.). Revista d'Arqueologia de Ponent, 22: 59-86.

- (2016): La guerra y el armamento celtibérico: estado actual. En Graells y Marzoli 2016: 229-273.

—; Sánchez, M.D.; Camacho, P. (2013): Las fíbulas del oppidum celtibérico de Contrebia Carbica. Jahrbuch des Römisch-Germanischen Zentralmuseum, 60: 297-352.

-; Sánchez, M.D. (2000-2001): Elementos de un taller de orfebre en Contrebia Carbica (Villas Viejas, Cuenca). Lucentum, XIX-XX: 127-148.

Luján, E. R.; García, J. M. (2011): A Greekman in the Iberian Street. Papers in Linguistics and Epigraphy in Honour of Javier de Hoz. (E. R. Luján; J. M. García, eds.): Innsbruicker Beiträge zur Sprachwissenschaft 140. Inssbruck.

Maele, S. ; Fossey, J.M. (1992.) : Fortificationes Antiquce. (S. Maele ; J.M. Fossey, eds.) Amsterdam.

Marsden, E.W. (1969): Greek and roman artillery: Historical development. Clarendon Press, Oxford.

Mayoral, V. (2016.): La revalorización de zonas arqueológicas mediante el empleo de técnicas no destructivas. (V. Mayoral, ed.) Anejos del archivo Español de arqueología LXXV, 25-40

- (2016): Arqueología aérea y teledetección en el suroeste peninsular. La experiencia del proyecto Riteca II. En Mayoral 2016: 25-40.

Mena, P.; Velasco, F., Gras, R. (1988): La ciudad de Fosos de Bayona (Huete, Cuenca): Datos de las dos últimas campañas de excavación. I Congreso de Historia de Castilla-La Mancha (Ciudad Real 1985), tomo IV, Ciudad Real: 183-190.

Mínguez, J.A., Ferreruela, A. (2012) : Las ciudades de La Cabañeta y La Corona. Su función en los inicios de la romanización del valle medio del Ebro. En Belarte et al. 2012 : 257-273.

Moret, P. (1996 ): Les fortifications ibériques de fin de l'âge du bronze à la conquête romaine. Publications de La Casa de Velázquez. Madrid.

-; Quesada, F. (2002): La guerra en el mundo ibérico y celtibérico (ss. VI-II a. de C.). Seminario celebrado en la Casa de Velázquez, Madrid, 1996. (P. Moret: F. Quesada, coords.) Madrid.

Morillo, A. (2003): Los establecimientos temporales militares: conquista y defensa del territorio en la Hispania republicana. En Morillo et al. 2003: 41-81.

-, (2008): Criterios arqueológicos de identificación de los campamentos romanos en Hispania. Salduie, 8: 73-95.

-, Cadiou, F. y Hourcade, D. (2003): Defensa y territorio en Hispania de los escipiones a Augusto, (A. Morillo; F. Cadiou; D. Hourcade, coords.) Universidad de León y Casa de Velázquez, Madrid.

Musson, C. (2005): Rilevamento aéreo: vantaggi e limiti. En Campana et al. 2005: 35-58.

Olcina, M.H.; Soler, J.A. (2000): Scripta in Honores Enrique A. Llobregat Conesa, (M.H Olcina y J.A. Soler, eds), Alicante. 
Pérez, A. (2014): Coaliciones en el mundo celtibérico. En Burillo y Chorda 2014: 161-175.

Pérez Blasco, M.F. (2014): El alto Chacón y su relación con el área ibérica de Levante en época sertoriana. En Burillo y Chorda 2014: 467-474.

Picazo, J.V.; Rodanés, J.M. (2009): Cabezo de la Cruz (La Muela, Zaragoza). Los poblados del bronce final y primera Edad del Hierro. Gobierno de Aragón. Zaragoza

Pina, F. (2003): ¿Existió una política romana de urbanización en el nordeste de la Península Ibérica. Habis 24: $77-94$

— (2006): Imperialismo y estrategia militar en la conquista de Hispania Citerior (218-153 a.C.). En Burillo 2006: 71-80.

- (2011): Etnia, ciudad y provincia en la Hispania republicana. En Caballos y Lefevbre 2011: 39-53.

Quesada, F, (2003): De los fosos de Troya a la línea Sigfrido. Las piedras hincadas en el contexto de la historia de las fortificaciones. En Alonso et al. 2003: 69-101.

- (2008): Armas de Grecia y Roma. La esfera de los libros. Madrid.

Rodríguez, O.; Portilla, R.; Sastre, J.C.; Fuentes, P. (2015): Fortificaciones en la edad del hierro. Control de los recursos y el territorio. (O. Rodríguez; R. Portilla; J.C. Sastre; P. Fuentes, coords.) Congreso internacional de Fortifiaciones. zamora

Romeo, F. (2002): Las fortificaciones ibéricas del valle medio del Ebro y el problema de los influjos mediterráneos. En Moret y Quesada 2002: 153-188.

- (2005): Notas para un glosario de términos referentes a los sistemas defensivos en la antigüedad. Salduie, 5: 189-213.

- (2006): Reflexiones sobre el asedio de la ciudad ibérica del cabezo de Alcalá de Azaila. Museo de Zaragoza. Boletín, 18. 2004: 25-55.

- (2016): Conflictos y destrucciones en la Celtiberia Citerior entre los siglos III y I a.C.: el yacimiento de El Calvario, en Gotor, Zaragoza. Lucentum XXXV: 65-90.

- (2017): Piedra y plomo: la honda frente a los asentamientos fortificados del noreste de la península ibérica a partir del siglo III a. C. y su repercusión en los sistemas defensivos. Gladius, XXXVII: 00-00. doi: 10.3989 /gladius.2017.04

-; Royo, J.I. (2015): Los sistemas defensivos de los asentamientos y ciudades ibéricas del valle medio del Ebro del siglo III a. I a.C. Éxito y olvido de un modelo tardío. En Rodríguez et al. 2015: 341-360.

Royo, J.I.; Cebolla, J.L. (2005): La búsqueda de la Bilbilis celtibérica. En Jimeno 2005: 153-160.

-; Romeo, F. (2015): Poblados fortificados de la $1^{\text {a }}$ edad del hierro en el valle medio del Ebro: origen, tipología e implicaciones. En Rodríguez et al. 2015: 361-385.

Sáenz, C.; Martín-Bueno, M. (2015): La ciudad celtíbero-romana de Valdeherera (Calatayud, Zaragoza). Prensas de la Universidad de Zaragoza, Monografías arqueológicas 50.

Sacristán, J.D. (2005): Clunia. El confín de la Celtiberia. En Jimeno 2005: 183-190.

Sánchez, E.; Pérez, A.; García, A. (2015): Fronteras y agregaciones políticas en Celtiberia: datos para un debate. Cuadernos de Prehistoria de la Universidad Autónoma de Madrid, 41: 69-85

Skov, E.T. (2013): Experimentation in Sling Weaponry: Effectiveness of and Archaeological Implications for a World-Wide Primitive Technology. Anthropology Department Theses and Dissertations. Paper 30, Nebraska, University of Nebraska-Lincoln.

Tabernero, C.; Heas, E.; Benito, J.C.; Sanz, A. (2005): Segotia Lanka. En Jimeno 2005: 197-204.

Torres, J. de (2013): La tierra sin límites. Territorio, sociedad e identidades en el Valle Medio del Tajo (s. IX-I a.C.). Zona Arqueológica 16. Alcalá de Henares.

Torres, J.; Martínez, A.; Vacas, D., (2015): El Oppidum de Monte Bernorio, estructura defensiva y proyección territorial. En Rodríguez et al. 2015: 109-128.

Vicente, J.; Escriche, C.; Punter, M.P. (1985): Las construcciones defensivas del Cabezo de San Pedro (Oliete, Teruel). Boletín del museo de Zaragoza, 4: 187-215.

-; Punter, M.P.; Ezquerra, B. (1997): La catapulta tardo-republicana y otro equipamiento militar de La Caridad (Teruel). Journal of Roman Military Equipement Studies, 8: 167-199.

-; Punter, M.P.; Escriche, C.; Herce, A.I. (2001): La Caridad (Caminreal, Teruel). La casa urbana hispanorromana, Institución Fernando el Católico, Zaragoza: 81-129

-; Punter, M.P.; Ezquerra, B. (2016): La ciudad romana de La Caridad (Caminreal, Teruel). Síntesis de 32 años de intervención Arqueológica. Actas del I Congreso de Arqueología y Patrimonio Aragonés. Zaragoza: 243-253. 